\title{
Is there a correlation between complete blood count parameters and nutritional risk score 2002, geriatric nutritional risk index and nutric score in geriatric patients admitted to intensive care unit
}

\author{
๑Ramazan Baldemir, @Güler Eraslan Doğanay \\ University of Health Sciences, Ankara Atatürk Chest Diseases and Thoracic Surgery Training and Research Hospital, Anesthesiology and \\ Reanimation Clinic, Ankara, Turkey
}

Cite this article as: Baldemir R, Eraslan Doğanay G. Is there a correlation between complete blood count parameters and nutritional risk score 2002, geriatric nutritional risk index and nutric score in geriatric patients admitted to intensive care unit. Anatolian Curr Med J 2022; 4(1); 89-94.

\begin{abstract}
ASBTRACT
Aim: Malnutrition is a common condition especially in geriatric patients admitted to intensive care. There are various screening tools to be used in the evaluation of nutritional status in geriatric patients hospitalized in intensive care. However, a laboratory test has not been found yet for nutritional status assessment. With this study, we aimed to investigate whether there is a correlation between NLR, PLR, and complete blood count parameters at the time of admission to the intensive care unit and NRS-2002, GNRI, and mNutric Score measured in the intensive care unit.

Material and Method: This retrospective study was performed in a tertiary intensive care unit of a Chest Diseases Hospital. Patients aged 65 and over were included in the study. Demographic data, length of stay in intensive care, complete blood count on the day of admission to the intensive care unit, albumin value, NLR, PLR, NRS-2002, GNRI, and mNutric Score values were recorded.

Results: A total of 218 geriatric patients were analyzed. It was determined that $72.5 \%$ of the patients were at medium/high risk in terms of nutritional risk according to the GNRI classification, 76.6\% were at high risk according to NRS-2002, and $84.9 \%$ were at high risk according to the mNutric score. According to the GNRI, the MPV values were statistically significantly higher $(\mathrm{p}<0.05)$. According to the biserial correlation analysis, there is a statistically significant correlation between GNRI and MPV in the positive direction $(\mathrm{p}<0.05)$. The cut-off value for MPV was determined as 7.895 in terms of nutritional risk assessment

Conclusion: It was observed that the majority of geriatric patients in the intensive care unit were at high risk for malnutrition according to nutritional scores. It was determined that the MPV value of the patients in the intermediate/high-risk group for GNRI was significantly higher and there was a positive correlation between MPV and GNRI. The cut-off value for MPV was determined as 7.895 in terms of nutritional risk assessment. We think that MPV can be used practically in nutritional risk scoring in geriatric patients hospitalized in the intensive care unit.
\end{abstract}

Keywords: Complete blood count, geriatric nutritional risk index, intensive care, nutric score, nutritional risk score-2002, mean platelet volume

\section{INTRODUCTION}

Malnutrition is a common condition especially in geriatric patients admitted to intensive care (1). There are various screening tools to be used in the evaluation of nutritional status in geriatric patients hospitalized in intensive care (1). Nutritional status assessment in these patients is frequently performed with geriatric nutritional risk index (GNRI), nutritional risk score-2002 (NRS2002), and modified nutrition risk in the critically ill score (mNUTRIC Score) (1-6). However, a laboratory test has not been found yet for nutritional status assessment. However, the nutritional status of the patients affects the length of stay in the hospital and intensive care unit and is a determinant in prognosis and mortality $(7,8)$. Therefore, it is important to evaluate the nutritional status quickly and practically, especially in geriatric patients.

The complete blood count is performed in almost all patients for whom blood tests are requested and it is a practical method. In some studies, it has been shown that neutrophil/lymphocyte ratio (NLR) and platelet/ lymphocyte ratio (PLR) are parameters that can determine the prognosis in patients (9-11). However, we could not find any research on whether there is a correlation 
between the scoring used in the nutritional status assessment of geriatric patients admitted to the intensive care unit and the parameters of the complete blood count. With this study, we aimed to investigate whether there is a correlation between NLR, PLR, and complete blood count parameters at the time of admission to the intensive care unit and NRS-2002, GNRI, and mNutric Score measured in the intensive care unit. If a correlation is detected, a more practical nutritional status assessment can be made in geriatric patients.

\section{MATERIAL AND METHOD}

Our study was performed in a tertiary intensive care unit after the approval of the Keçiören Training and Resarch Hospital Clinical Researchs Ethics Committee (Date: 11.05.2021, Decision No: 2012-KAEK-15/2306). All procedures were performed adhered to the ethical rules and principles of the Helsinki Declaration.

The data of patients admitted to the intensive care unit with respiratory failure between January 2018 and December 2018 were scanned retrospectively from patient files. Demographic data such as age, gender, height, weight, body mass index, length of stay in intensive care, complete blood count on the day of admission to the intensive care unit, albumin value, NLR, PLR, NRS-2002, GNRI, and Nutric Score values were recorded. NLR was calculated by dividing the absolute neutrophil count by the absolute lymphocyte count. PLR was calculated by dividing the absolute platelet count by the absolute lymphocyte count. NRS-2002 is routinely calculated by the nutrition team for each patient admitted to the intensive care unit. NRS-2002 is calculated based on the patient's body mass index, weight loss in the last 3 months, appetite status, and severe disease status. Nutric score calculation is based on patient's age, Apache-II score (Acute Physiology and Chronic Health EvaluationII), SOFA score (Sequential Organ Failure Assessment Score), number of co-morbidities, Interleukin-6(IL-6), and the length of hospital stay before admission to the intensive care unit (12). In our study, the modified Nutric score (mNutric score) calculated without taking into account IL-6 was used. GNRI was calculated from the formula $[1.489 \mathrm{X}$ albumin $(\mathrm{g} / \mathrm{L})]+[41.7$ (kilo/ideal weight)] (13). Ideal weight was calculated with the formula [(Height-100) -(Height-150/4)] for men and with the Formula [(Height-100) -(Height-150/2,5)] for women (13). The nutritional risk status of the patients was determined as follows: GNRI $\geq 92$; (low risk/No risk), GNRI < 92; (Moderate Risk/High Risk), NRS-2002 $\leq 4$; (Low Risk), NRS-2002>4; (High Risk), Nutric score $\leq 4$; (Low Risk), Nutric score $>4$; (High Risk) (1,13-15). If the weight of the patients was more than their ideal weight, the weight/ideal weight ratio was accepted as 1 (13).
Patients under the age of 65, patients with a diagnosis of hematological malignancy, patients hospitalized in the intensive care unit for less than 24 hours, and those with insufficient data required for the study were excluded from the study.

\section{Statistical Analysis}

Data analyses were performed by using SPSS for Windows, version 22.0 (SPSS Inc., Chicago, IL, United States). Whether the distribution of continuous variables was normal or not was determined by the Kolmogorov Smirnov test. Levene test was used for the evaluation of homogeneity of variances. Unless specified otherwise, continuous data were described as mean \pm SD for normal distributions, and median (interquartile range) for skewed distributions. Categorical data were described as the number of cases (\%). Statistical analysis differences in normally distributed variables between two independent groups were compared by Student's t-test, Mann Whitney $\mathrm{U}$ tests were applied for comparisons of the not normally distributed data. Concordance between nutritional scores was evaluated by Cohen's Kappa Analysis. İt was evaluated degrees of the relation between variables with point biserial correlation. It was accepted $p$-value $<0.05$ as a significant level on all statistical analysis.

\section{RESULTS}

The number of patients hospitalized in the intensive care unit with respiratory failure was 348.232 patients were 65 years of age or older. 3 patients were excluded because they stayed in the intensive care unit for less than 24 hours, and 11 patients were excluded because their data were missing. A total of 218 patients were analyzed (Figure 1).

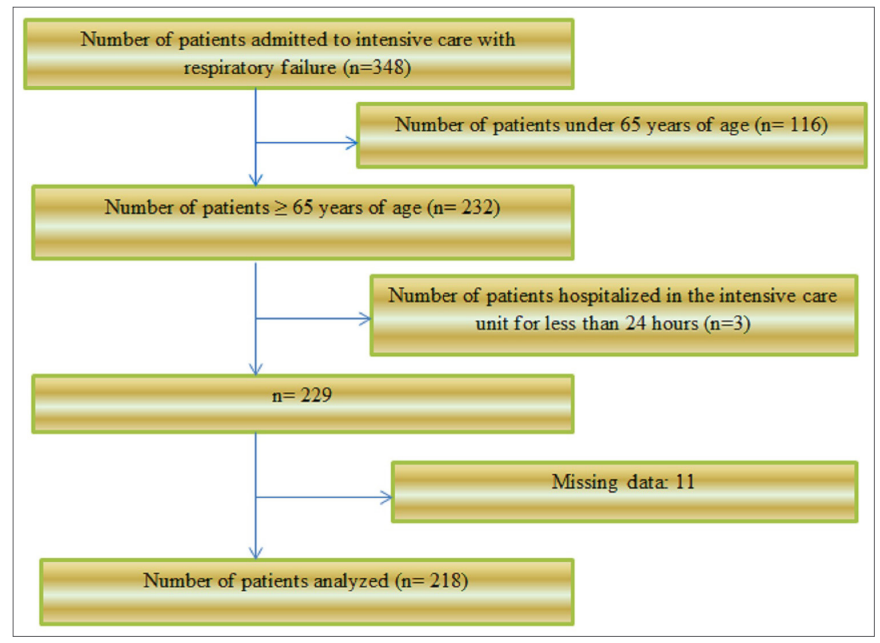

Figure 1. Flow chart of the patients.

The demographic data of the patients, their diagnoses, the status of receiving mechanical ventilator support, and the length of stay in the intensive care unit are given in Table 1. 
It was determined that $72.5 \%$ of the patients were at medium/high risk in terms of nutritional risk according to the GNRI classification, $76.6 \%$ were at high risk according to NRS-2002, and $84.9 \%$ were at high risk according to the mNutric score.

According to the GNRI, the RBC, hemoglobin, and hematocrit values of the medium/high-risk group were statistically significantly lower than the no-risk/low-risk group, while the $\mathrm{MCH}, \mathrm{MCHC}$, and MPV values were statistically significantly higher $(\mathrm{p}<0.05)$ (Table 2$)$.

\begin{tabular}{|c|c|}
\hline $\mathrm{n}: 218$ & AllPatients \\
\hline \multicolumn{2}{|l|}{ Gender, n (\%) } \\
\hline Male & $121(55.5 \%)$ \\
\hline Female & $97(44.5 \%)$ \\
\hline Age, mean $\pm S D$ & $78.28 \pm 7.43$ \\
\hline $\mathrm{BMI}\left(\mathrm{kg} / \mathrm{m}^{2}\right)$, mean $\pm \mathrm{SD}$ & $25.38 \pm 5.83$ \\
\hline Mechanical Ventilator Support, n (\%) & $101(46.3 \%)$ \\
\hline Type 1 Respiratory Failure, n (\%) & $82(37.6 \%)$ \\
\hline Type 2 Respiratory Failure, n (\%) & $136(62.4 \%)$ \\
\hline \multicolumn{2}{|l|}{ Diagnosis of malignancy, $\mathrm{n}(\%)$} \\
\hline No & $189(86.7 \%)$ \\
\hline Lung malignancy & $23(10.6 \%)$ \\
\hline COPD, n (\%) & $143(65.6 \%)$ \\
\hline ICU stay,days, median (IQR) & $3.5(4)$ \\
\hline \multicolumn{2}{|c|}{$\begin{array}{l}\text { Continuous variables are expressed as either the mean }+ \text { Standard deviation (SD) } \\
\text { or median (interquartile range) and categorical variables are expressed as either } \\
\text { frequency (percentage). } \\
\text { BMI: Body mass index, ICU: Intensive care unit, COPD: chronic obstructive } \\
\text { pulmonary disease, IQR: interquartile range }\end{array}$} \\
\hline
\end{tabular}

Table 2. NLR, PLR and hemogram values of patients according to GNRI risk classification

\begin{tabular}{|c|c|c|c|}
\hline & \multicolumn{2}{|c|}{ GNRI Risk } & \multirow[b]{2}{*}{$\mathbf{P}$} \\
\hline & $\begin{array}{l}\text { No-risk/Low- } \\
\text { risk (n:60) }\end{array}$ & $\begin{array}{l}\text { Medium/High- } \\
\text { risk (n:158) }\end{array}$ & \\
\hline WBC, $\times 10^{3} / \mu \mathrm{L}$ & $10.35(5.75)$ & $10.95(7.50)$ & 0.319 \\
\hline Lymphocyt count, $\times 10^{3} / \mu \mathrm{L}$ & $0.82(1.07)$ & $0.84(0.96)$ & 0.993 \\
\hline Monocyte count, $\times 10^{3} / \mu \mathrm{L}$ & $0.44(0.54)$ & $0.47(0.59)$ & 0.518 \\
\hline Neutrophil count, $\times 10^{3} / \mu \mathrm{L}$ & $8.81(5.00)$ & $8.94(7.44)$ & 0.160 \\
\hline Eosinophil count, $\times 10^{3} / \mu \mathrm{L}$ & $0.01(0.04)$ & $0.01(0.07)$ & 0.427 \\
\hline Basophil count, $\times 10^{3} / \mu \mathrm{L}$ & $0.03(0.05)$ & $0.03(0.05)$ & 0.811 \\
\hline $\mathrm{RBC}, \times 10^{6} / \mu \mathrm{L}$ & $4.57 \pm 0.88$ & $4.06 \pm 0.85$ & $<0.001$ \\
\hline Hemoglobin, g/dL & $11.85(3.25)$ & $10.90(2.80)$ & 0.009 \\
\hline Hematocrit, \% & $39.51 \pm 7.98$ & $35.42 \pm 7.06$ & $<0.001$ \\
\hline $\mathrm{MCV}, \mathrm{fL}$ & $86.30(10.40)$ & $88.10(8.80)$ & 0.430 \\
\hline $\mathrm{MCH}, \mathrm{pg}$ & $27.05(3.95)$ & $28.20(3.60)$ & 0.040 \\
\hline $\mathrm{MCHC}, \mathrm{g} / \mathrm{dL}$ & $30.91 \pm 1.62$ & $31.67 \pm 1.60$ & 0.002 \\
\hline RDW, \% & $17.85(4.65)$ & $16.85(3.50)$ & 0.209 \\
\hline Platelet $\times 10^{3} / \mu \mathrm{L}$ & $241.70 \pm 98.77$ & $228.55 \pm 95.98$ & 0.371 \\
\hline MPV, fL & $8.22(1.95)$ & $8.80(1.68)$ & 0.016 \\
\hline PCT, \% & $0.20 \pm 0.08$ & $0.20 \pm 0.08$ & 0.956 \\
\hline PDW, \% & $17.55(1.85)$ & $17.40(2.40)$ & 0.494 \\
\hline NLR & $9.54(12.54)$ & $10.01(12.90)$ & 0.501 \\
\hline PLR & $319.29(316.39)$ & $240.82(290.49)$ & 0.423 \\
\hline \multicolumn{4}{|c|}{$\begin{array}{l}\text { Continuous variables are expressed as either the mean } \pm \text { Standard deviation (SD) or } \\
\text { median (interquartile range) and categorical variables are expressed as either frequency } \\
\text { (percentage).Continuous variables were compared with student test tor mann whitney } \\
\text { u test, and categorical variables were compared using Pearson'schi-square test or fisher } \\
\text { exact test. Statistically significant p-values are in bold. } \\
\text { NLR: neutrophil / lymphocyte rate; LMR: lymphocyte/monocyte rate; PLR: platelet/ } \\
\text { lymphocyte rate; WBC: White blood cell; RBC: Red blood cell; MCV: mean corpuscular } \\
\text { volume; MCH: mean corpuscular hemoglobin; MCHC: mean corpuscular hemoglobin } \\
\text { concentration; RDW: red cell distribution width; MPV: mean platelet volume; PCT: } \\
\text { platelet crit; PDW: platelet distribution width. GNRI: geriatric nutritional risk index }\end{array}$} \\
\hline
\end{tabular}

There are no statistically significant difference between the groups in terms of NLR, PLR, and hemogram values according to NRS-2002 and mNutric score risk groups $(\mathrm{p}>0.05)$.

According to the biserial correlation analysis, there is a statistically significant correlation between GNRI and $\mathrm{RBC}$ and Hematocrit in the negative direction, and between MCHC and MPV in the positive direction $(\mathrm{p}<0.05)($ Table 3$)$.

Table 3. Correlation Analysis between Nutritional Scoring and NLR, PLR and Hemogram Values

\begin{tabular}{|c|c|c|c|c|}
\hline & & GNRI Risk & NRS -2002 & $\begin{array}{c}\text { mNutric } \\
\text { Score }\end{array}$ \\
\hline \multirow{2}{*}{$\mathrm{WBC}, \times 10^{3} / \mu \mathrm{L}$} & $\mathrm{r}$ & 0.024 & -0.119 & 0.066 \\
\hline & $\mathrm{p}$ & 0.720 & 0.079 & 0.331 \\
\hline \multirow{2}{*}{$\begin{array}{l}\text { Lymphocyt Count, } \\
\times 10^{3} / \mu \mathrm{L}\end{array}$} & $\mathrm{r}$ & -0.109 & 0.009 & 0.037 \\
\hline & $\mathrm{p}$ & 0.108 & 0.891 & 0.590 \\
\hline \multirow{2}{*}{$\begin{array}{l}\text { Monocyte Count, } \\
\times 10^{3} / \mu \mathrm{L}\end{array}$} & $\mathrm{r}$ & 0.046 & -0.075 & 0.083 \\
\hline & $\mathrm{p}$ & 0.501 & 0.269 & 0.220 \\
\hline \multirow{2}{*}{$\begin{array}{l}\text { Neutrophil Count, } \\
\times 10^{3} / \mu \mathrm{L}\end{array}$} & $\mathrm{r}$ & 0.087 & -0.139 & 0.051 \\
\hline & $\mathrm{p}$ & 0.203 & 0.041 & 0.454 \\
\hline \multirow{2}{*}{$\begin{array}{l}\text { Eosinophil Count, } \\
\times 10^{3} / \mu \mathrm{L}\end{array}$} & $\mathrm{r}$ & 0.030 & -0.038 & 0.032 \\
\hline & $\mathrm{p}$ & 0.662 & 0.572 & 0.637 \\
\hline \multirow{2}{*}{$\begin{array}{l}\text { Basophil Count, } \\
\times 10^{3} / \mu \mathrm{L}\end{array}$} & $\mathrm{r}$ & -0.068 & 0.053 & 0.054 \\
\hline & $\mathrm{p}$ & 0.320 & 0.433 & 0.427 \\
\hline \multirow{2}{*}{$\mathrm{RBC}, \times 10^{6} / \mu \mathrm{L}$} & $\mathrm{r}$ & -0.254 & -0.005 & -0.031 \\
\hline & $\mathrm{p}$ & $<0.001$ & 0.938 & 0.646 \\
\hline \multirow{2}{*}{ Hemoglobin, g/dL } & $\mathrm{r}$ & -0.025 & 0.048 & 0.022 \\
\hline & $\mathrm{p}$ & 0.711 & 0.477 & 0.749 \\
\hline \multirow{2}{*}{ Hematocrit, \% } & $\mathrm{r}$ & -0.243 & 0.021 & -0.007 \\
\hline & $\mathrm{p}$ & $<0.001$ & 0.754 & 0.913 \\
\hline \multirow{2}{*}{$\mathrm{MCV}, \mathrm{fL}$} & $\mathrm{r}$ & 0.049 & 0.048 & 0.039 \\
\hline & $\mathrm{p}$ & 0.471 & 0.481 & 0.569 \\
\hline \multirow{2}{*}{$\mathrm{MCH}, \mathrm{pg}$} & $\mathrm{r}$ & 0.075 & -0.107 & 0.039 \\
\hline & $\mathrm{p}$ & 0.270 & 0.115 & 0.567 \\
\hline \multirow{2}{*}{$\mathrm{MCHC}, \mathrm{g} / \mathrm{dL}$} & $\mathrm{r}$ & 0.207 & 0.017 & -0.019 \\
\hline & $\mathrm{p}$ & 0.002 & 0.801 & 0.783 \\
\hline \multirow{2}{*}{ RDW, \% } & $\mathrm{r}$ & -0.080 & -0.098 & 0.024 \\
\hline & $\mathrm{p}$ & 0.241 & 0.147 & 0.728 \\
\hline \multirow{2}{*}{ Platelet, $\times 10^{3} / \mu \mathrm{L}$} & $\mathrm{r}$ & -0.061 & -0.023 & -0.109 \\
\hline & $\mathrm{p}$ & 0.371 & 0.732 & 0.107 \\
\hline \multirow{2}{*}{ MPV,fL } & $\mathrm{r}$ & 0.137 & 0.041 & 0.033 \\
\hline & $\mathrm{p}$ & 0.044 & 0.551 & 0.624 \\
\hline \multirow{2}{*}{ PCT, \% } & $\mathrm{r}$ & 0.004 & -0.011 & -0.105 \\
\hline & $\mathrm{p}$ & 0.956 & 0.874 & 0.121 \\
\hline \multirow{2}{*}{ PDW, \% } & $\mathrm{r}$ & -0.029 & -0.001 & 0.015 \\
\hline & $\mathrm{p}$ & 0.675 & 0.989 & 0.828 \\
\hline \multirow{2}{*}{ NLR } & $\mathrm{r}$ & 0.069 & -0.036 & -0.046 \\
\hline & $\mathrm{p}$ & 0.312 & 0.594 & 0.501 \\
\hline \multirow{2}{*}{ PLR } & $\mathrm{r}$ & 0.031 & 0.041 & -0.094 \\
\hline & $\mathrm{p}$ & 0.653 & 0.547 & 0.169 \\
\hline
\end{tabular}

NLR: neutrophil / lymphocyte rate, LMR: lymphocyte/monocyte rate, PLR: platelet/ lymphocyte rate, WBC: White blood cell, RBC: Red blood cell, MCV: mean corpuscular volume, MCH: mean corpuscular hemoglobin, MCHC: mean corpuscular hemoglobin volume, MCH: mean corpuscular hemoglobin, MCHC: mean corpuscular hemoglobin concentration, RDW: red cell distribution width, MPV: mean platelet volume, PCT: platelet crit, PDW: platelet distribution width, GNRI: geriatric nutritional risk index,
NRS: Nutritional risk score, mNutric: modified nutrition risk in critically ill 
In the ROC analysis, the area under the curve (AUC) for MPV was calculated as 0.606 and was found to be statistically significant $(\mathrm{p}<0.05)$. When the cut-off value of 7.895 was accepted as the cut-off value in terms of MPV level, the sensitivity was calculated as $77.8 \%$, the specificity as $43.3 \%$. (Table 4) (Figure 2)

Table 4. ROC Curve Analysis Results by Geriatric Nutritional Risk Index for Mean Platelet Volume

\begin{tabular}{|lc|}
\hline & MPV \\
\hline AUC & 0.606 \\
AUC for 95\% CI & $(0.519-0.593)$ \\
P values & 0.016 \\
CutOff & 7.895 \\
Sensitivity & $77.8 \%$ \\
Specificity & $43.3 \%$ \\
PPV & $78.3 \%$ \\
NPV & $42.6 \%$ \\
LR+ & 1.37 \\
LR- & 0.52 \\
\hline AUC: area under curve, PPV: positivepredictivevalue, NPV: negativepredictivevalue, \\
LR+: positivelikelihoodrati, LR-: negativelikelihoodratio
\end{tabular}

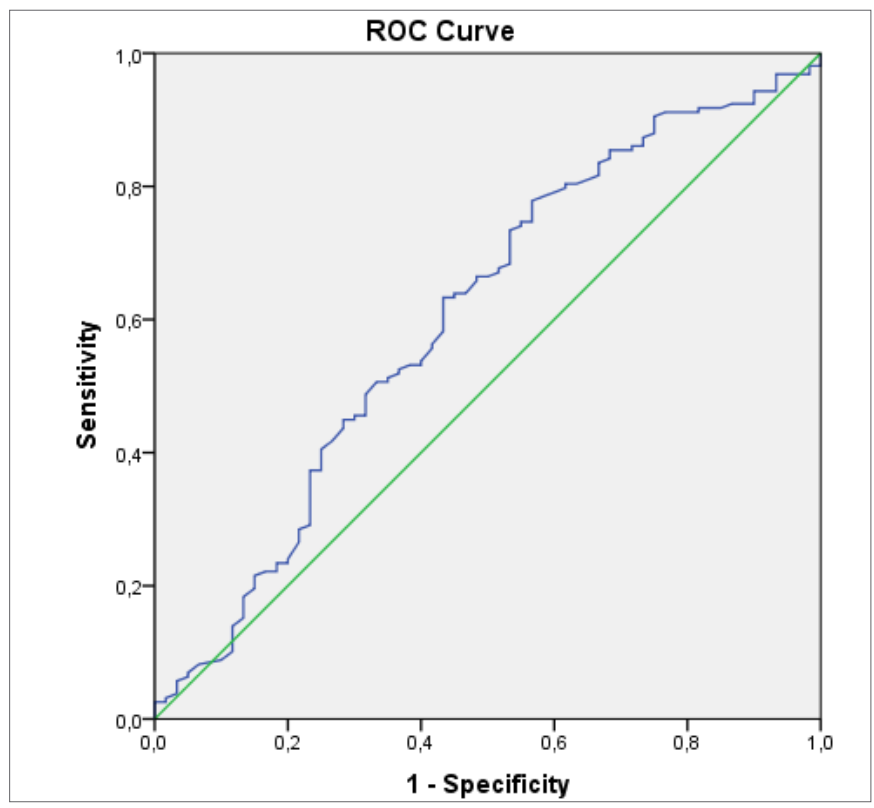

Figure 2. ROC curve for Mean Platelet Volume. ROC: Receiver Operating Characteristic

\section{DISCUSSION}

In our study, it was seen that the majority of patients hospitalized in the intensive care unit with respiratory failure were at high risk for malnutrition according to nutritional scores. According to NRS-2002 and mNutric Score, there was no difference in NLR, PLR, and hemogram values between low and high-risk patients. However, according to GNRI, the MPV values of the medium/high-risk group were found to be statistically significantly higher than the no-risk/low-risk group. In addition, there is a low level of statistically significant correlation between GNRI and MPV in the positive direction. As a result of the ROC analysis, a cut-off value of 7.895 was determined for MPV.

The number of geriatric patients hospitalized in the intensive care unit with respiratory failure is gradually increasing (1). Geriatric patients are handled differently from other patients due to increased comorbidity and pharmacokinetic and pharmacodynamic differences $(16,17)$. Studies indicate that advanced age is a risk factor for morbidity and mortality (18-20). We think that nutritional evaluation in geriatric patients should be handled differently. Malnutrition is an important condition that is frequently encountered in the elderly population and leads to muscle weakness and the development of various infections if not detected and treated in a timely manner (1). Therefore, it is very important to detect malnutrition or the risk of malnutrition quickly, especially in geriatric patients. NRS-2002 is not specifically designed for intensive care patients. The mNutric score, on the other hand, does not contain any nutritional parameters (21). However, both scorings are used for nutritional risk assessment in intensive care patients $(1,3,21)$. Nutric score has a limited prediction for the initiation of early nutritional therapy in the admission of patients to the intensive care unit(22). In addition, both NRS-2002 and mNutric Score were investigated to predict mortality in intensive care patients $(1,3)$. It is not possible to obtain detailed information about the nutritional status of geriatric patients admitted to the intensive care unit. The information provided by their relatives may not be sufficient. It is stated that GNRI can be used easily and objectively as a malnutrition screening tool in geriatric patients (1). GNRI, on the other hand, is a screening tool that integrates serum albumin and BMI for nutritional assessment in geriatric patients (23). Studies indicate that GNRI can also be used as a prognostic indicator in many diseases (24-26). For this reason, the effect of GNRI on nutritional assessment and mortality in geriatric patients hospitalized in the intensive care unit was investigated and it was stated that it could predict mortality in patients hospitalized in the intensive care unit with respiratory failure (1). However, recently, studies have been carried out to evaluate the prognosis of patients using laboratory parameters $(9,13,27)$. It is known that NLR and PLR, which can be calculated especially with hemogram parameters, are used in the evaluation of prognosis in various diseases (9-11). However, there are limited studies evaluating the relationship between hemogram parameters and nutritional status $(28,29)$. In a study examining the relationship between lymphocyte count and nutritional status in geriatric patients, it was stated that lymphocyte count could be used as a nutritional marker in hospitalized geriatric patients (28). In another 
study, it was stated that lymphocyte count was not a good nutritional marker in geriatric patients (29). However, these studies were not conducted specifically for geriatric patients admitted to the intensive care unit. Our study is the first in the literature to evaluate the nutritional status with hemogram parameters in geriatric patients hospitalized in the intensive care unit with respiratory failure. In our study, similar to the result of Kuzuya M, et al (29), no relationship was found between lymphocyte count and nutritional assessment in geriatric patients.

In our study, there was no difference between the groups in terms of NLR, PLR, and hemogram values according to NRS-2002 and mNutric score risk groups. However, according to GNRI, the RBC, hemoglobin, and hematocrit values of the medium/high-risk group were lower than the no-risk/low-risk group, while the $\mathrm{MCH}$, $\mathrm{MCHC}$, and MPV values were found to be significantly higher. While there is no difference according to NRS2002 and mNutric score risk groups, the difference in laboratory parameters according to GNRI risk groups may be due to the fact that GNRI is a screening tool designed specifically for the geriatric age group.

MPV is evaluated as an indicator of platelet function (30). It is also stated that it is associated with the inflammatory process and reflects the severity of the disease (31-35). MPV value may increase in chronic respiratory diseases and various diseases (36). In a study, it was stated that high MPV levels were associated with increased mortality in geriatric patients (37). In our study, it was determined that the MPV value of the patients in the intermediate/ high-risk group for GNRI was significantly higher and there was a positive correlation between MPV and GNRI. In addition, as a result of the ROC analysis, a cut-off value of 7.895 was determined for MPV. The cut-off value of 7,895 that we have obtained can be used in a practical way in determining the nutritionally intermediate/highrisk patients in geriatric patients admitted to the intensive care unit.

There are some limitations in our study. First of all, our study is a single-center and retrospective study. Accordingly, the nutritional treatments applied to the patients and the changes in the nutritional status of the patients after these treatments could not be evaluated. In addition, the prognosis of the patients after the intensive care unit could not be evaluated.

\section{CONCLUSION}

As a result, the majority of patients hospitalized in the intensive care unit with respiratory failure in our clinic are geriatric patients. It was observed that the majority of geriatric patients in the intensive care unit were at high risk for malnutrition according to nutritional scores.
In our study, it was determined that the MPV value of the patients in the intermediate/high-risk group for GNRI was significantly higher and there was a positive correlation between MPV and GNRI. In addition, the cut-off value for MPV was determined as 7.895 in terms of nutritional risk assessment. We think that MPV can be used practically in nutritional risk scoring in geriatric patients hospitalized in the intensive care unit, but it would be beneficial to bring different studies to the literature with prospective and multicenter studies.

\section{ETHICAL DECLARATIONS}

Ethics Committee Approval: The study was initiated with the approval of the Keçiören Training and Research Hospital Clinical Researchs Ethics Committee (Date: 11.05.2021, Decision No: 2012-KEAK-15/2306).

Informed Consent: Because the study was designed retrospectively, no written informed consent form was obtained from patients.

Referee Evaluation Process: Externally peer-reviewed.

Conflict of Interest Statement: The authors have no conflicts of interest to declare.

Financial Disclosure: The authors declared that this study has received no financial support.

Author Contributions: All of the authors declare that they have all participated in the design, execution, and analysis of the paper and that they have approved the final version.

\section{REFERENCES}

1. Yenibertiz D, Cirik MO. The comparison of GNRI and other nutritional indexes on short-term survival in geriatric patients treated for respiratory failure. Aging Clin Exp Res 2021; 33: 611-7.

2. Javid Mishamandani Z, Norouzy A, Hashemian SM, et al. Nutritional status of patients hospitalized in the intensive care unit: A comprehensive report from Iranian hospitals. J Crit Care 2019; 54: 151-8.

3. Machado Dos Reis A, Marchetti J, Forte Dos Santos A, Franzosi OS, Steemburgo T. Nutric score: isolated and combined use with the NRS-2002 to predict hospital mortality in critically Ill patients. JPEN J Parenter Enteral Nutr 2020; 44: 1250-6.

4. Lew CCH, Yandell R, Fraser RJL, Chua AP, Chong MFF, Miller M. Association between malnutrition and clinical outcomes in the intensive care unit: a systematic review. J Parenter Enteral Nutr 2017; 41: 744-58.

5. Lin YM, Wang M, Sun NX, Liu YY, Yin TF, Chen C. Screening and application of nutritional support in elderly hospitalized patients of a tertiary care hospital in China. PLoS One 2019; 14: e0213076.

6. Bouillanne O, Morineau G, Dupont C, et al. Geriatric Nutritional Risk Index: a new index for evaluating at-risk elderly medical patients. Am J Clin Nutr 2005; 82: 777-83.

7. Álvarez-Hernández J, Planas Vila M, León-Sanz M, et al. Prevalence and costs of malnutrition in hospitalized patients. Nutr Hosp 2012; 27: 1049-59.

8. Agarwal E, Miller M, Yaxley A, Isenring E. Malnutrition in the elderly: a narrative review. Maturitas 2013; 76: 296-302. 
9. Kaya T, Açıkgöz SB, Yıldırım M, Nalbant A, Altaş AE, Cinemre $\mathrm{H}$. Association between neutrophil-to-lymphocyte ratio and nutritional status in geriatric patients. J Clin Lab Anal 2019; 33: e22636.

10. Yıldırım Ö, Bayram M, Özmen RS, et al. Evaluation of hematological indices in terms of COVID-19 related mortality and ICU admission. J Health Sci Med 2021; 4: 666-70.

11. Lee JS, Kim NY, Na SH, Youn YH, Shin CS. Reference values of neutrophil-lymphocyte ratio, lymphocyte-monocyte ratio, platelet-lymphocyte ratio, and mean platelet volume in healthy adults in South Korea. Medicine (Baltimore) 2018; 97: e11138.

12. de Vries MC, Koekkoek WK, Opdam MH, van Blokland D, van Zanten AR. Nutritional assessment of critically ill patients: validation of the modified Nutric score. Eur J Clin Nutr 2018; 72: 428-35.

13. Tang S, Xie H, Kuang J, Gao F, Gan J, Ou H. The value of geriatric nutritional risk index in evaluating postoperative complication risk and long-term prognosis in elderly colorectal cancer patients. Cancer Manag Res 2020; 12: 165-75.

14. McClave SA, Taylor BE, Martindale RG, et al. Guidelines for the Provision and Assessment of Nutrition Support Therapy in the Adult Critically Ill Patient: Society of Critical Care Medicine (SCCM) and American Society for Parenteral and Enteral Nutrition (A.S.P.E.N.). J Parenter Enteral Nutr 2016; 40: 159-211.

15. de Vries MC, Koekkoek WK, Opdam MH, van Blokland D, van Zanten AR. Nutritional assessment of critically ill patients: validation of the modified Nutric score. Eur J Clin Nutr 2018; 72: 428-35

16. Zengin $\mathrm{M}$, Alagoz A. Comparison of thoracic epidural analgesia and thoracic paravertebral block applications in the treatment of acute pain after thoracotomy in geriatric patients. Cureus 2021 22: 18982.

17. Cavalieri TA. Managing pain in geriatric patients. J Osteopath Med 2007; 107: 10-6.

18. Du RH, Liang LR, Yang CQ, et al. Predictors of mortality for patients with COVID-19 pneumonia caused by SARS-CoV-2: a prospective cohort study. Eur Respir J 2020; 55: 2000524.

19. Tekyol D, Hökenek NM. Comparison of the ability of the shock index, modified shock index and age shock index to predict mortality in geriatric patients with COVID-19 pneumonia. J Health Sci Med 2021; 4: 634-8.

20. Aydin N. COVID-19 ve palyatif bakım. J Med Palliat Care 2021; 2: 54-57.

21. Heyland DK, Dhaliwal R, Jiang X, Day AG. Identifying critically ill patients who benefit the most from nutrition therapy: the development and initial validation of a novel risk assessment tool. Crit Care 2011; 15: 268.

22. Al-Kalaldeh M, Suleiman K, Al-Kalaldeh O. Prognostic performance of nutric score in quantifying malnutrition risk in the critically Ill in congruence with the bioelectrical impedance analysis. Nutr Clin Pract 2020; 35: 559-66.

23. Cereda E, Klersy C, Pedrolli C, et al. The Geriatric Nutritional Risk Index predicts hospital length of stay and in-hospital weight loss in elderly patients. Clin Nutr 2015; 34: 74-8

24. Miyake $H$, Tei H, Fujisawa M. Geriatric nutrition risk index is an important predictor of cancer-specific survival, but not recurrence-free survival, in patients undergoing surgical resection for non-metastatic renal cell carcinoma. Curr Urol 2017; 10: 26-31.

25. Yamana I, Takeno S, Shimaoka H, et al. Geriatric Nutritional Risk Index as a prognostic factor in patients with esophageal squamous cell carcinoma -retrospective cohort study. Int J Surg 2018; 56: 44-8

26. Shoji F, Matsubara T, Kozuma Y, et al. Preoperative Geriatric Nutritional Risk Index: A predictive and prognostic factor in patients with pathological stage I non-small cell lung cancer. Surg Oncol 2017; 26: 483-8
27. Güngörer B. Baseline demographic, clinical and laboratory risk factors for predicting admission to intensive care unit in patients diagnosed with COVID-19 in the emergency department. Anatolian Curr Med J 2021; 3: 279-83.

28. Leandro-Merhi VA, Bráz VN, Aquino JL. Is total lymphocyte count related to nutritional markers in hospitalized older adults? Arq Gastroenterol 2017; 54: 79-82.

29. Kuzuya M, Kanda S, Koike T, Suzuki Y, Iguchi A. Lack of correlation between total lymphocyte count and nutritional status in the elderly. Clin Nutr 2005; 24: 427-32.

30. Ak R, Doğanay F. Relationship between mean platelet volume and intensive care unit requirement in COVID-19 patients. J Health Sci Med 2021; 4: 353-7.

31. Sit M, Aktas G, Ozer B, et al. Mean platelet volume: an overlooked herald of malıgnant thyroid nodules. Acta Clin Croat 2019; 58 : 417-20.

32. Bilgin S, Aktas G, Kahveci G, Atak BM, Kurtkulagi O, Duman TT. Does mean platelet volume/lymphocyte count ratio associate with frailty in type 2 diabetes mellitus? Bratisl Lek Listy 2021; 122: 116-9.

33. Sincer I, Gunes Y, Mansiroglu AK, Cosgun M, Aktas G. Association of mean platelet volume and red blood cell distribution width with coronary collateral development in stable coronary artery disease. Postepy Kardiol Interwencyjnej 2018; 14: 263-9.

34. Önder S, Ozturk M. How does omalizumab affect the immunoinflammatory response in patients with chronic spontaneous urticaria? Cutan Ocul Toxicol 2020; 39: 31-5.

35. Kridin K, Shihade W, Zelber-Sagi S. Mean platelet volume in pemphigus vulgaris. Angiology 2018; 69: 303-7.

36. Korniluk A, Koper-Lenkiewicz OM, Kamińska J, Kemona $\mathrm{H}$, Dymicka-Piekarska V. Mean platelet volume (MPV): new perspectives for an old marker in the course and prognosis of inflammatory conditions. Mediators Inflamm 2019; 2019: 9213074.

37. Şatıroğlu Ö, Durakoğlugil ME, Uydu HA, et al. The relationship between mean platelet volume and in-hospital mortality in geriatric patients with ST segment elevation myocardial infarction who underwent primary percutaneous coronary intervention. Cardiovascular Innovations and Applications 2019; 4: $135-41$. 